\title{
Insights into secrets along the pollen tube pathway in need to be discovered
}

\author{
Ana Lúcia Lopes ${ }^{1,2,4}$, Diana Moreira', Maria João Ferreira ${ }^{1}$, Ana Marta Pereira ${ }^{3}$ and Sílvia Coimbra ${ }^{1,4, *,(D)}$ \\ ${ }^{1}$ Departamento de Biologia, Faculdade de Ciências da Universidade do Porto, Porto, Portugal \\ 2 Biosystems and Integrative Sciences Institute - BiolSI, Porto, Portugal \\ ${ }^{3}$ Dipartimento di Bioscienze, Università Degli Studi di Milano, Milano, Italy. \\ ${ }^{4}$ Sustainable Agrifood Production Research Centre - GreenUPorto, Vairão, Portugal
}

All authors contributed equally to this paper.

* Correspondence: scoimbra@fc.up.pt

Received 31 October 2018; Editorial decision 5 February 2019; Accepted 8 February 2019

Editor: Christine Raines, University of Essex, UK

\begin{abstract}
The process of plant fertilization provides an outstanding example of refined control of gene expression. During this elegant process, subtle communication occurs between neighboring cells, based on chemical signals, that induces cellular mechanisms of patterning and growth. Having faced an immediate issue of self-incompatibility responses, the pathway to fertilization starts once the stigmatic cells recognize a compatible pollen grain, and it continues with numerous players interacting to affect pollen tube growth and the puzzling process of navigation along the transmitting tract. The pollen tube goes through a guidance process that begins with a preovular stage (i.e. prior to the influence of the target ovule), with interactions with factors from the transmitting tissue. In the subsequent ovular-guidance stage a specific relationship develops between the pollen tube and its target ovule. This stage is divided into the funicular and micropylar guidance steps, with numerous receptors working in signalling cascades. Finally, just after the pollen tube has passed beyond the synergids, fusion of the gametes occurs and the developing seed-the ultimate aim of the process-will start to mature. In this paper, we review the existing knowledge of the crucial biological processes involved in pollen-pistil interactions that give rise to the new seed.
\end{abstract}

Keywords: Double fertilization, pollen-pistil interaction, pollen tube guidance, receptors, sexual plant reproduction, signalling molecules.

\section{Introduction}

When writing to his friend Joseph Hooker about the puzzling phenomenon of the angiosperm fossil record, Charles Darwin referred to an 'abominable mystery': how did the dominance of the angiosperms emerge and how did flowers, their reproductive units, help them to thrive and evolve (Crepet, 2000)? Even now, this long-lasting mystery still remains to be solved. The information that we have already gathered about the angiosperms life cycle has helped us to better understand this phenomenon, but new players are continually being found that interact during the sexual plant reproduction process to integrate the overall network of the male-female cross-talk that leads to the generation of new seeds.

We can liken our study of angiosperm reproduction to deciphering a map in a treasure hunt, where the promised 'treasure' is the seeds that will form the next generation and ensure the continuation of the species. Along the way, we need 
to gather clues and trace the pathways in order to untangle the 'abominable mystery'.

It is always a good idea to begin with the basics: angiosperms change from a sporophytic diploid generation to a gametophytic haploid generation. Inside the flowers, meiotic divisions in stamens and ovules generate two different types of spores, the microspores and the megaspores, respectively. After mitotic divisions, these spores produce the gametophytes that will produce the gametes. The double-fertilization event occurs when the two identical male gametes fuse with the two female gametes, the oosphere and the central cell, thus establishing a new diploid sporophytic generation and completing the plant's life cycle (Yadegari and Drews, 2004).

Arabidopsis thaliana is an important, well-studied model plant, because it is small, with a well-sequenced genome, and a rapid life cycle (Meinke, 1994). Inside the Arabidopsis carpel, ovules are enclosed within the ovary, and in each ovule there is a single megasporocyte that undergoes meiosis and produces four haploid megaspores. Only one of these survives to produce the functional megaspore (FM), the others dying as a result of programmed cell death (PCD). After three successive mitotic divisions, the FM forms at the chalaza a female polygonum gametophyte with seven cells and eight nucleithe embryo sac (Yadegari and Drews, 2004; Palanivelu and Tsukamoto, 2012). At the micropylar pole near the opening of the two integuments, two synergids with their filiform apparatus (resulting from the complex invagination of the synergid cell walls) are present surrounding the egg cell. At the opposite (chalazal) pole there are three antipodal cells, and the central zone is occupied by the central cell with two polar nuclei, which fuse before the arrival of the pollen tube (PT). Over $70 \%$ of the flowering plants share this type of female gametophyte (Maheshwari and Johri, 1950; Yadegari and Drews, 2004; Zhou and Dresselhaus, 2019).

The male gametophytes (also known as pollen grains) are formed inside the anther. The mature pollen grain initially has two haploid cells: a vegetative and a generative cell. The generative cell undergoes mitosis, thus originating the two male gametes. In most plants, this mitosis occurs during pollen-tube growth, but in Arabidopsis it occurs while the pollen grain is still within the anther. The vegetative cell forms the PT that carries and releases the male gametes inside the female gametophyte (McCormick, 1993, 2004; Lord and Russell, 2002).

\section{Drawing the treasure map-double fertilization}

The aimed treasure - the new seed generation - is only formed in flowering plants as a result of the double-fertilization process, the unique key biological feature that has granted the angiosperms their success. The pathway begins once the stigmatic cells recognize a compatible pollen grain, at which point it becomes properly hydrated and forms the PT that will carry the two sperm cells into the ovule embryo sac (Fig. 1). The rapid and controlled navigation of the PT is enabled by a series of communications and consequent signalling cascades that lead to various interactions between the PT and the sporophytic

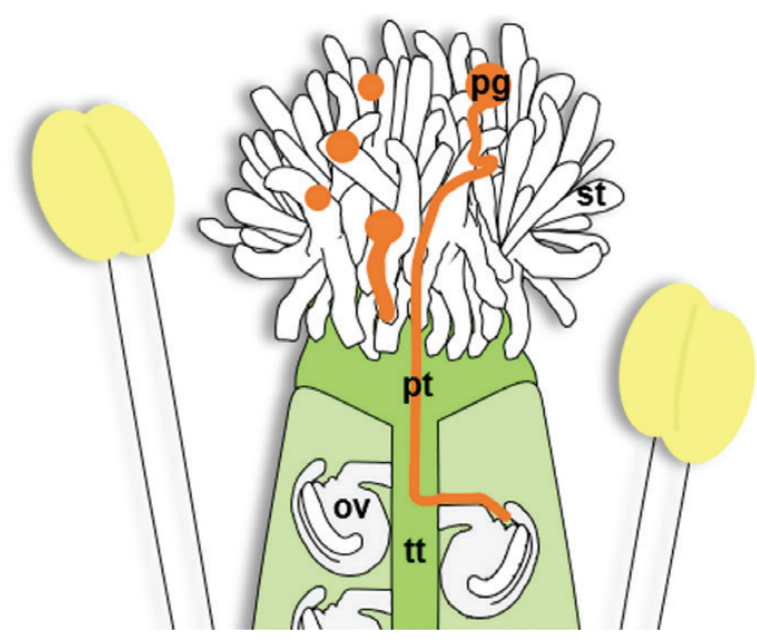

Fig. 1. Schematic representation of the journey of a pollen tube through an Arabidopis pistil. st, stigma; ov, ovules; pg, pollen grain; pt, pollen tube; $\mathrm{tt}$, transmitting tissue.

and gametophytic female tissues. The PT grows through the extracellular matrix of cells of the female reproductive tissue, namely the stigma, style, and transmitting tissue (TT) (Yadegari and Drews, 2004), until it receives the signals that direct it into an ovule. Once close to the ovule, the PT emerges from the septum and the double-fertilization begins. Having grown along the funiculus, the PT finally reaches the entrance to the embryo sac, the micropyle, and then passes through the filiform apparatus of one of the two synergids, where it stops growing, ruptures, and releases its two sperm cells. It is now time for the process of simultaneous fertilization to occur, where one sperm cell fuses with the egg cell to generate the embryo, while the other fuses with the central cell to form the endosperm, the basal tissue that will provide nourishment to the embryo (Palanivelu and Tsukamoto, 2012; Beale and Johnson, 2013; Dresselhaus and Franklin-Tong, 2013; Pereira et al., 2014). After PT burst, the penetrated synergid dies by PCD (Higashiyama et al., 2001; Zhou and Dresselhaus, 2019; Dresselhaus and Franklin-Tong, 2013), and the remaining synergid will fuse with the endosperm after successful fertilization of both the female gametes.

This process of organogenesis involves refined control of gene expression, based on subtle communication occurring between neighbouring cells and on chemical signals that induce cellular mechanisms of patterning and growth, all of which are tightly constrained in a complex regulatory network. In this review, we will examine every individual step from the adhesion of the pollen grains to the stigma onwards that leads to the generation of the new seed, mapping the role of each player in each tissue in order to untangle the complex regulatory network of interacting genes.

\section{Step by step: the clues}

\section{First interaction of the pollen and stigma}

When a pollen grain lands at the stigma cells, it has to immediately face self-incompatibility (SI) responses, a pre-fertilization 
barrier aimed at avoiding the negative effects associated with inbreeding depression (Losdat et al., 2014) (Fig. 2). Selective inhibition begins in order to prevent self-fertilization and thus to grant the gene pool and genetic variation of plants (Nasrallah, 2017; Bedinger et al.,2017). This process is controlled by the multiallelic S-locus in many plant species (Fujii et al., 2016).

The complex exocytic subunit Exo70A1 in the Arabidopsis stigma accepts a compatible pollen grain and acts to cause polarized secretion from the stigmatic cells and is proposed to provide vesicles containing aquaporins, which improve the water permeability of the pollen grain, allowing it to hydrate, and also provide cell wall-modifying enzymes that allow the PT to grow into the stigma ( Safavian et al., 2015; Goring, 2017). Phosphatidylinositol-4-phosphate (PI4P) is crucial in this initial step, as evidenced by the fact that mutants with low levels of PI4P on the stigma have slower hydration rates and maternal fertility defects due to failed pollinations (Chapman and Goring, 2011).

The Arabidopsis VACUOLAR SORTING 41 protein (AtVPS41) is also a controlling factor, as the PTs of atvps 41 plants do not enter the female TT due to a compromised endocytic pathway (Hao et al., 2016). $\mathrm{Ca}^{2+}$ is an important intracellular signalling factor for the formation of the PT and its polarized growth (Iwano et al., 2004; Pereira et al., 2016a).

The mysterious arabinogalactan protein (AGP) family, which is always involved in distinct stages of the reproductive process, may also be essential regulatory components of PT growth (Lamport et al., 2018). The receptivity of apple blossom stigma depends on secretion of AGPs and their disappearance is linked with PT growth (Losada and Herrero, 2012). The molecular properties and periplasmic location of the classical AGPs (Lamport et al., 2006) make them the primary source of oscillations in cytosolic $\mathrm{Ca}^{2+}$, pectic plasticizers, working as $\mathrm{Ca}^{2+}$ signposts to the ovule (Lamport et al., 2018). AGPs present in the stigma cells and in growing PTs have roles in pollen-stigma interactions and pollen grain competence that initiate PT growth. The pollen-specific AGP6,AGP11,AGP23, and AGP40, are included in the PT endosome machinery (Costa et al., 2013; Pereira et al., 2016a).

The gene O-FUCOSYLTRANSFERASE1 (AtOFT1) plays a key role in PT penetration through the stigma-style interface and, based on genetic and physiological evidence, a Golgi-localised fucosyltransferase system may be needed for PT growth through the pistil tissues. Although as yet unknown, the substrates of AtOFT1 may include cell-surface receptors or structural proteins secreted into the extracellular matrix. A nearly sterile oft 1 phenotype should provide a means to determine how putative proteins OFTs are utilized within pollen-pistil interactions (Smith et al., 2018). Fasciclin-like AGPs (FLAs) are also recruited during this process, as FLA3 is expressed in the pollen grains and PTs and is involved in the development of microspores byaffecting cellulose deposition (Li et al., 2010).

\section{The puzzling navigation of the pollen tube along the transmitting tissue}

The rapid and controlled growth of the PT is enabled by an accurate communication network and signalling cascades during the pollen-pistil interactions (Figs 3, 4). The PT guidance process starts with 'preovular guidance', where any compatible PT travels in the extracellular matrix of the TT or channel from the stigma to the ovary without any influence from the target ovule, and later turns to 'ovular guidance' in which a specific relationship is formed between one PT and its ovule (Higashiyama and Takeuchi, 2015; Kanaoka and Higashiyama, 2015; Mizuta and Higashiyama, 2018).

Mechanical, chemotropic, geometric, and physiological orientation mechanisms may explain the precise growth of PTs towards the ovary (Heslop-Harrison, 1987; Lush, 1999; Cameron and Geitmann, 2018). There is a strict balance between cell turgor and cell wall resistance to maintain the shape

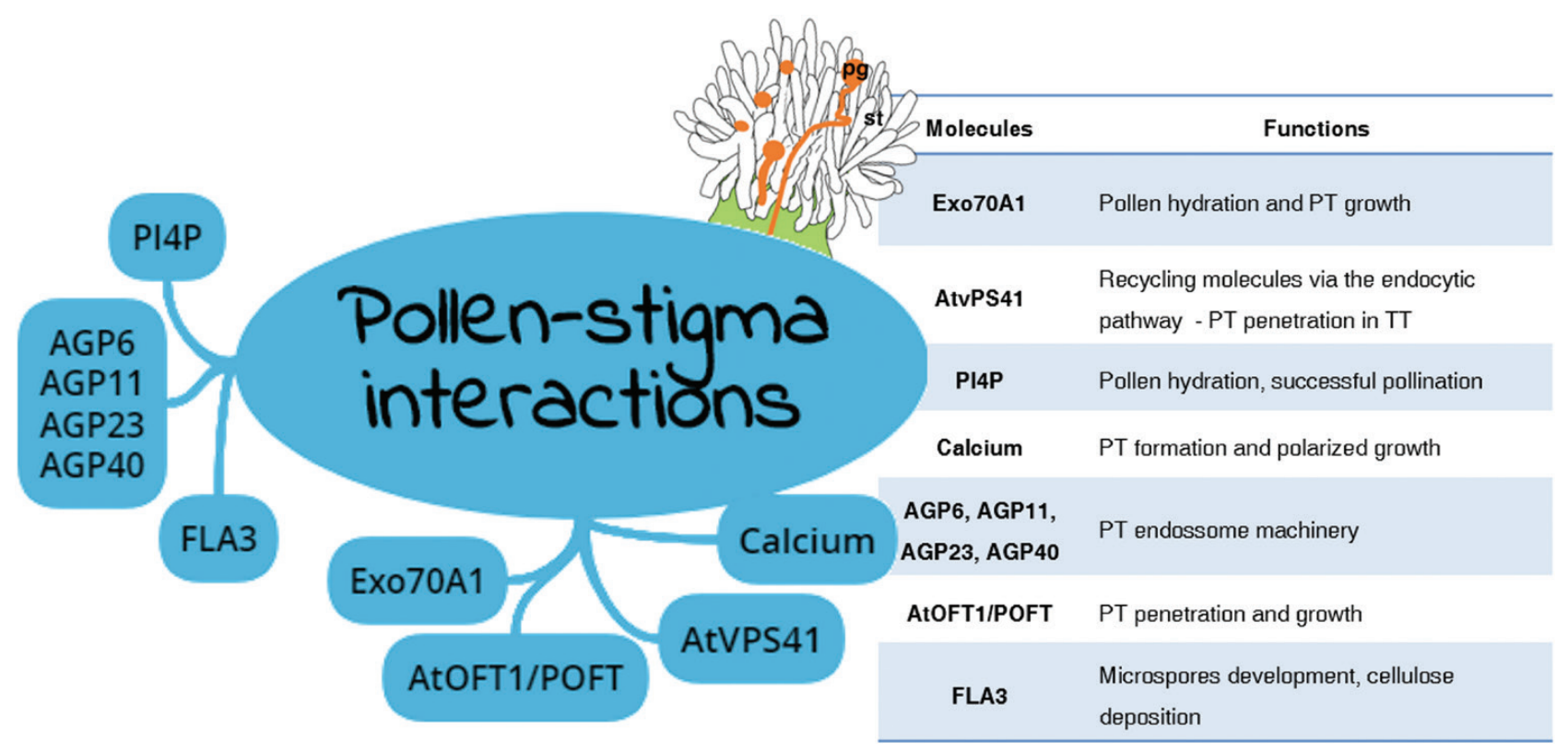

Fig. 2. The players involved in pollen-stigma interactions and their roles. PT, pollen tube; $\Pi$, transmitting tissue. 


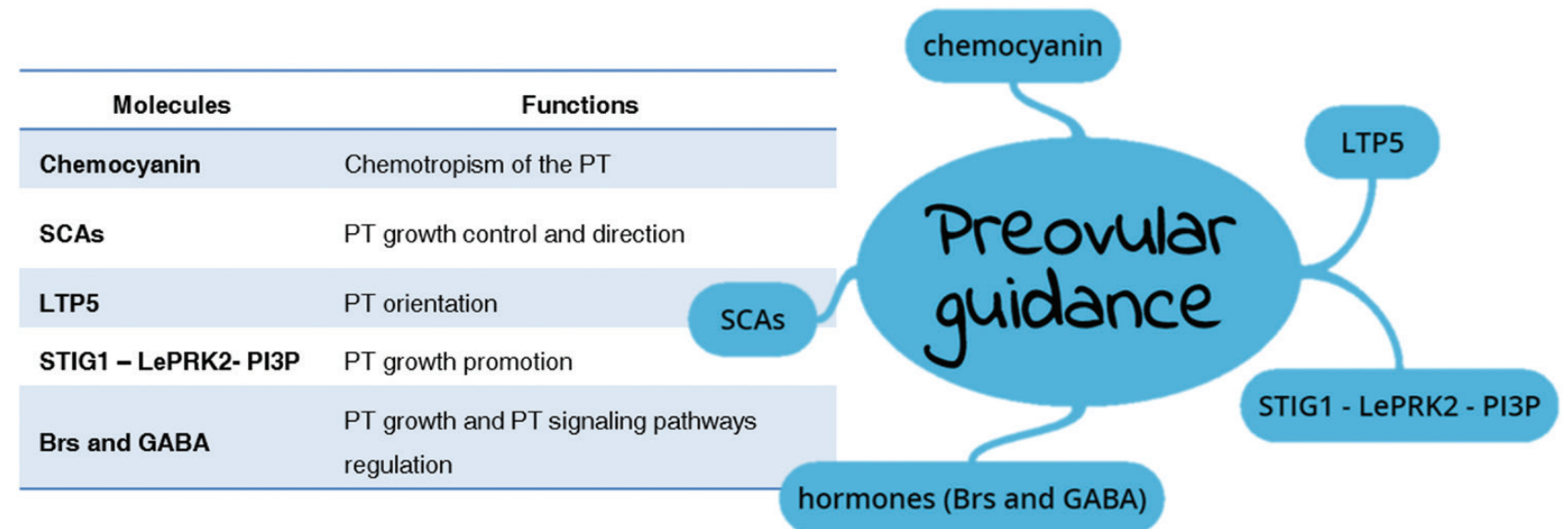

Fig. 3. The players involved in the preovular guidance stage and their their roles. PT, pollen tube.

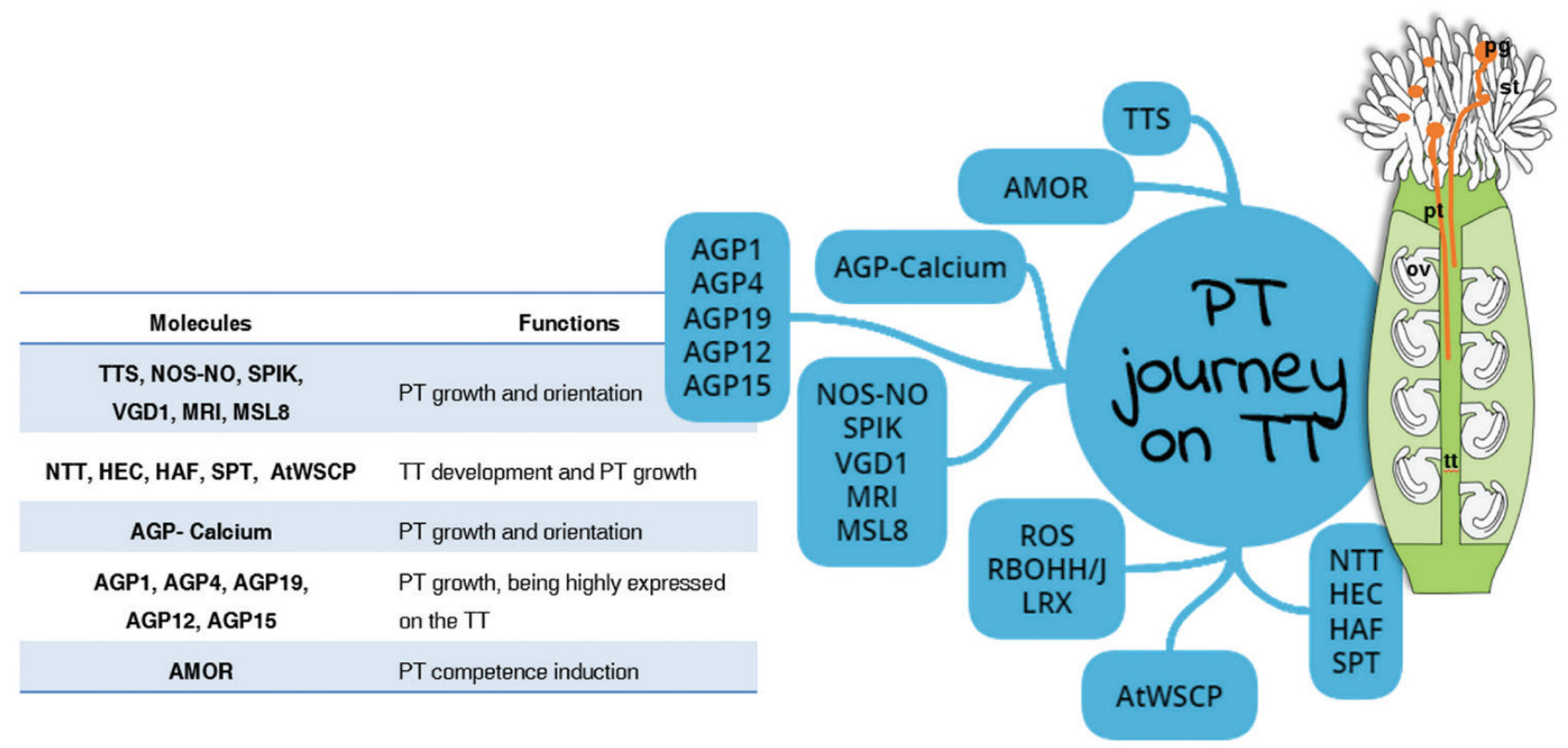

Fig. 4. The players involved in navigation of the pollen tube (PT) along the transmitting tissue (TT) and their roles.

of the PT, enabling the tip to expand and grow and preventing the loss of the cell integrity (Winship et al., 2011). Accurate cell wall assembly is fundamental for PT growth. The polysaccharide pectin, an essential component of the primary cell wall, interferes with the wall structure and flexibility during cell growth. Pectin methylesterase (PME) enzymes spatially and temporally control the de-esterification of pectin, essential for PT integrity. PTs become unstable when loosing de-esterified pectin. Arabidopis Vanguard1 (VGD1) encodes a pectin methylesterase, and the vgd1 mutant helps to demonstrate the importance of pectin in the cell wall for PT integrity as it presents cell bursting in vitro and delayed growth in vivo (Bosch and Hepler, 2005; Jiang et al., 2005). In addition, the $\mathrm{Cl}^{-}$channel MSL8 in Arabidopsis has been shown to cause precocious bursting of the PT before arriving at the synergids (Li and Yang, 2018). Enzymatic production of reactive oxygen species (ROS) also affects PT growth. Characterization of the NADPH oxidases RbohH and RbohJ (Respiratory burst oxidase homologs $\mathrm{H}$ and $\mathrm{J}$ ) in Arabidopsis has shown that the tip growth of the PT is severely impaired in the rbohH rbohJ double-mutant. Both RbohH and RbohJ, which have $\mathrm{Ca}^{2+}-$ binding EF-hand motifs, show $\mathrm{Ca}^{2+}$-induced ROS-producing activity at the PT tip of the plasma membrane. The extension of the PT slows down to couple the rates of exocytosis and cell expansion, possibly through $\mathrm{Ca}^{2+}$ influx and $\mathrm{K}^{+}$efflux (Kaya et al., 2014; Lassig et al., 2014). The affected amplitude and frequency of ion oscillation are detrimental to the precise coupling of the tip growth and the cell wall dynamics. The integrity of the PT depends on the cell wall composition and is controlled by its modifying enzymes and ROS, except for extensins (Jiang et al., 2005; Woriedh et al., 2013).

In Torenia fournieri, the PT has a unidirectional orientation (Higashiyama and Hamamura, 2008), and possibly does not need the female gametophyte (FG) for the growth of the PT from the stigma to the style (Sogo and Tobe, 2006). With preovular guidance in mind, chemocyanin in the stigma is found 
to induce PT chemotropism in Lilium longiflorum, with stigma cysteine-rich adhesins (SCAs) binding with the PT and allowing the chemocyanin to have physical access to the plasma membrane, thus controlling and directing the growth of the PT (Park et al., 2000; Kim et al., 2003). PT pectins may interact with the Arabidopsis LIPID TRANSFER protein 5 (LTP5) to facilitate guidance (Chae et al., 2009). In tomato, CYSTEINERICH STIGMA SPECIFIC PROTEIN 1 (STIG1) interacts with a KINASE 2-type pollen receptor (LePRK2) and with phosphatidylinositol 3-phosphate (PI3P) as a signal peptide to promote PT growth (Tang et al., 2004); In Arabidopsis, PT growth is promoted by pistil brassinosteroids (Vogler et al., 2014), with $\gamma$-aminobutyric acid (GABA) modulating the $\mathrm{Ca}^{2+}$ channels in the plasma membranes, thus regulating the PT signalling pathways (Palanivelu et al., 2003; Yu et al., 2014). During preovular guidance (Fig. 3), the growth of the PT is therefore enabled by several mechanisms (Mizuta and Higashiyama, 2018).

The TT that connects the stigma, style, and ovules supports the growth of PTs through an extracellular matrix (ECM) that is extremely rich in glycoproteins, polysaccharides, glycolipids, and AGPs (Pereira et al., 2015). The Arabidopsis TT is solid and composed of cylindrical cells (Lennon et al., 1998; Erbar, 2003) that facilitate PT development and nutrition (Faure et al., 2002; Crawford and Yanofsky, 2008). According to hormonal studies, the establishment of the TT may be controlled by both auxin and cytokinin, which are responsible for the tissue polarity (Deb et al., 2018) and thus may play a key role in the complex interactions that control PT growth.

In Nicotiana tabacum, the highly glycosylated TRANSMITTING TISSUE SPECIFIC (TTS) AGP proteins promote PT growth and guidance to the ovules (Cheung et al., 1995; Wu et al., 2001). Transcription factors (TFs) such as NO TRANSMITTING TRACT (NTT), HECATE 1 (HEC1), HEC2, HEC3, HALF FILLED (HAF), SPATULA (SPT), and water-soluble chlorophyll proteins (AtWSCP) are important for TT development because they induce the PCD the of the tissue after the PT has passed, which is also crucial for PT growth (Alvarez and Smyth, 2002; Crawford and Yanofsky, 2011; Boex-Fontvieille et al., 2015; Mizuta and Higashiyama, 2018). ntt mutants show abnormal development of the TT, together with defects and slower growth of the PT, and a reduced fertilization rate (Crawford et al., 2007). In addition, ntt mutants have lower levels of acidic polysaccharides, which is possibly related to AGP content as they are acidic glycoproteins associatied with the TT.

The PT may be guided by distinct cues, including $\mathrm{K}^{+}, \mathrm{Cl}^{-}$, $\mathrm{Ca}^{2+}$ (Hepler et al., 2006), glycoproteins (Sommer-Knudsen et al., 1998), ROS (Foreman et al., 2003), nitric oxide (Prado et al., 2008), and peptides (Qu et al., 2015) as well as other complex signalling networks that have not yet been elucidated (Leydon et al., 2015).

In Arabidopsis, the Shaker family $\mathrm{K}^{+}$channel, SPIK, affects PT development. Loss of SPIK leads to precocious bursting of the PT together with a delayed growth, suggesting a conserved role of $\mathrm{K}^{+}$homeostasis in PT growth and bursting (Mouline et al., 2002).

The presence of AGPs along the pathway from the stigma to the egg cell indicates that they also provide guidance cues
(Pereira et al., 2014,2016a). If pollen tubes grown in vitro acidify their growth medium (Feijo et al., 1995), it may indicate that in vivo they can dissociate AGP-Ca ${ }^{2+}$ of the TT, enabling the PT to create $\mathrm{Ca}^{2+}$ path to the ovule. The fertilization of multiple ovules can also be enabled by the cooperation of multiple PTs (Heslop-Harrison et al., 1985) together with an increase of $\mathrm{H}^{+}$ efflux and the release of $\mathrm{Ca}^{2+}$ from locally abundant AGP-Ca ${ }^{2+}$ (Lamport et al., 2018).

High levels of expression of AGP1, AGP4 (JAGGER), and AGP19 can be found alon the TT in Arabidopsis (Yang et al., 2007; Pereira et al., 2014, 2016a, 2016b). AGP19 has high expression in the style, ovary walls, TT, and siliques, and agp19 mutants have low flower production and smaller siliques (Yang et al., 2007). AGP12 and AGP15, which are also located along the PT pathway, can contribute nutritionally to its growth from the top of the stigma to the base of the pistil, and facilitate its movement, provide guidance to its targets, and possibly making it competent for being received by the embryo sac (Pereira et al., 2014).

An AGP side-chain fragment designated AMOR is the PT activation molecule for the response to the LURE guidance peptides of the synergids in Torenia (Okuda et al., 2009). AMOR has been identified as a methyl-Oglucuronosyl-b-Dgalactose (Mizukami et al., 2016), possibly a key component of the AGP $\mathrm{Ca}^{2+}$-binding motif, . AMOR has a differential localization in specific structures in the AG sugar chains, indicating that AG biosynthesis enzymes re control AGP functions and their sugar chains (Su and Higashiyama, 2018).

It is still not entirely clear how all the TT components interact with the PT and, irrespective of the importance of these interactions, the different components present in the TT point to a contact-mediated ability provided by the stigma and style for the PT to become aware of the signals that direct it to the ovule (Palanivelu and Preuss, 2006). The TT is thus a key tissue for the quick growth of the PT through the pistil, but it also provides it with the ability to move accurately towards the ovule (Fig. 4).

\section{Ovular guidance: funicular and micropylar}

The PT exits from the TT through a very narrow space between the cells of the septum (Palanivelu and Tsukamoto, 2012), interacting with all the quests and tissues that trigger its emergence (Higashiyama and Takeuchi, 2015), during a crucial transition phase from preovular to ovular guidance (Mizuta and Higashiyama, 2018). When the PT emerges from the septum, it enters a funicular guidance phase from the placenta along the funiculus, and then in enters a micropylar guidance phase where it navigates from the funiculus to the micropyle (Shimizu and Okada, 2000; Mizuta and Higashiyama, 2018). This pathway is dependent on signals from sporophytic tissues and from the female gametophyte (Pereira et al., 2016a) (Fig. 5).

In Arabidopsis, two $\mathrm{K}^{+}$transporters present in the $\mathrm{PT}$, CATION HYDROGEN EXCHANGER 21 (CHX21) and CHX23, are able to block growth along the funiculus. ch $\times 21$ ch $x 23$ double mutant show normal PT growth through the TT, but the tubes are unable to grow into the ovule because they 


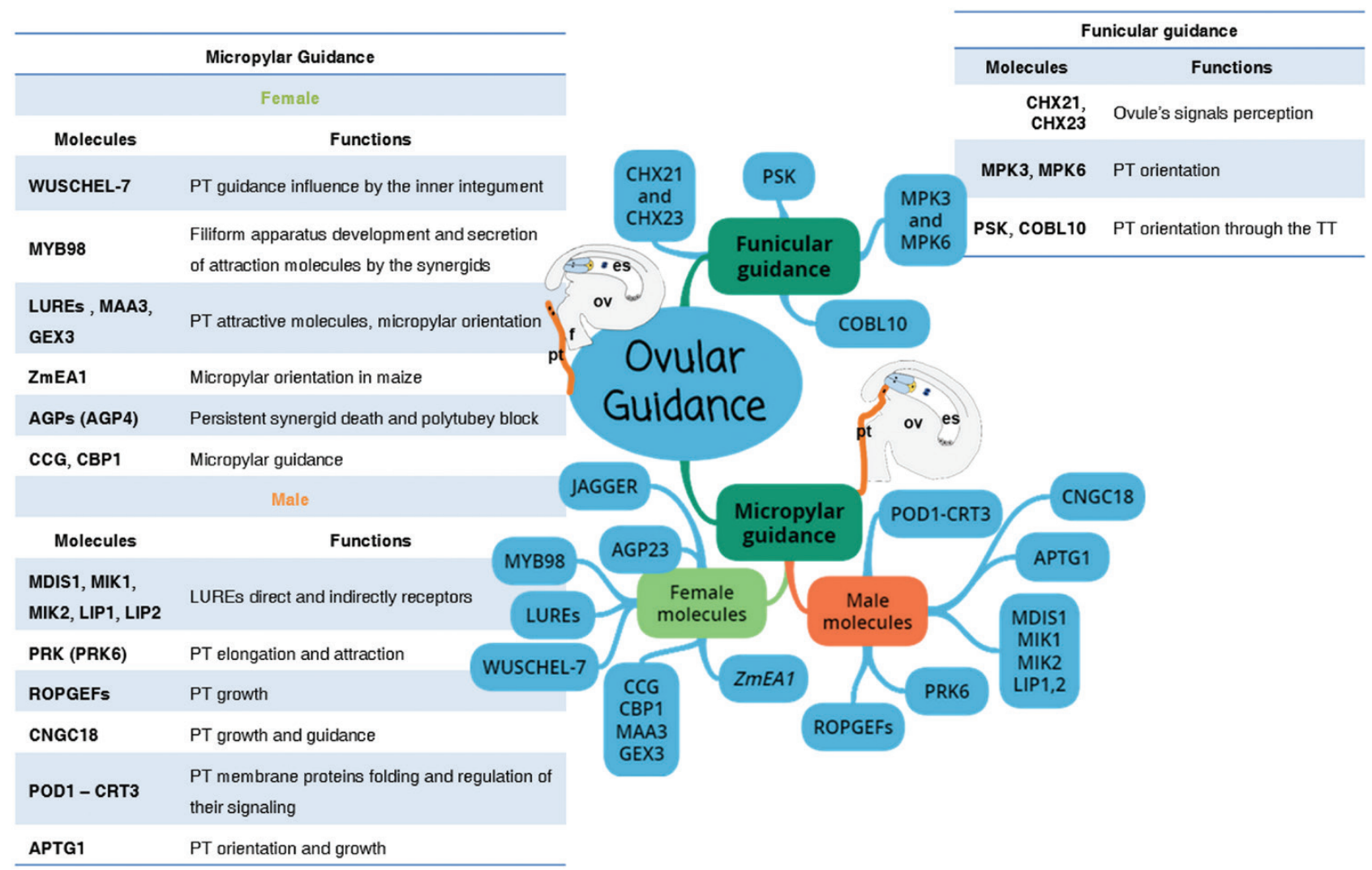

Fig. 5. The players involved in the ovular guidance stage, divided in funicular and micropylar guidance steps, and their roles. PT, pollen tube; $\Pi$, transmitting tissue.

are incapable to perceive the signals that come from the ovules ( $\mathrm{Lu}$ et al., 2011). PT competence for signalling is also dependent on MITOGEN-ACTIVATED PROTEIN KINASE (MPK3) and MPK6 (Guan et al., 2014), and the mpk3 mpk6 double-mutant has PTs that are defective in the funicular guidance phase. PTs can only pass through the TT with the controlling help of PHYTOSULFOKINE (PSK), as mutants show very low fertilization rates and loss of funicular orientation (Stührwohldt et al., 2015). Our knowledge of the mechanisms that regulate this stage is increasing but it remains incomplete, and studies are ongoing to determine whether there are additional guidance cues.

ABNORMAL POLLEN TUBE GUIDANCE 1 (APTG1), a mannosyltransferase (Dai et al., 2014), acts in the glycosylphosphatidylinositol (GPI) synthesis of the COBRALIKE 10 protein (COBL10) (Li et al., 2013). This protein, located at the tip of the PT, plays a crucial role in its orientation and growth. Mutations in COBL10 generate gametophytic male sterility due to low PT growth and defective directional sensing in the female TT. The formation of the apical pectin cap and the cellulose microfibrils are defective in the PTs of the cobl10 mutant (Li et al., 2013).

After the funicular guidance period, the PT enters the micropylar guidance stage. On reaching the micropylar region, the PT passes through an opening between the ovule integuments until it reaches one of the synergid cells, which are active and typically secretory cells (Huang and Russell, 1992). The wuschel-7 (wus-7) mutant has a short inner integument (Lora et al., 2019), with 65\% of wus-7 ovules showing no PTs emergence in the micropyle, and and 35\% of its ovules show defective embryo sacs. These results suggest that the short inner integument has a partial effect on PT guidance. It has long been known that the presence of a functional FG influences the attraction of the PT to the ovule (Ray et al., 1997; Shimizu and Okada, 2000), and it has now been established that it is the structure that produces the ovular-attraction molecules (Takeuchi and Higashiyama, 2016). Based on evidence from T. fournieri, the synergids are the female cells responsible for the ovular attraction of the PT. Torenia has a bare embryo sac, which is projected to the outside of the ovule through the micropyle when mature, thus allowing easy access to the embryo sac cells. It has been shown in vitro that PTs are attracted directly to the bare embryo sacs and hence do not leave the micropylar region, due to the production of attraction signals by the embryo sac (Higashiyama et al., 2001). Laser ablation performed on different gametophytic cells has determined that the synergids provide guidance to the PT via diffusible chemical signals (Higashiyama et al., 1998, 2001; Higashiyama and Hamamura, 2008; Horade et al., 2013).

An equivalent scenario happens in Arabidopsis with the MYB98 TF expressed in the synergids. The myb98 mutant has an abnormal filiform apparatus, which blocks the secretion of attractant molecules and hence the PT cannot find the micropyle (Kasahara et al., 2005; Punwani et al., 2008). The interaction between the egg and central cells is also important for ovular guidance, since laser disruption of the egg cell or the polar nucleus of the central cell can severely inhibit attraction of the PT (Susaki et al., 2015). Thus the synergids act together 
with the egg and central cells to regulate the PT attraction during the last stage of its journey (Zhou and Dresselhaus, 2019; Pereira et al., 2016b; Mizuta and Higashiyama, 2018).

Hence there are attractant molecules produced by the synergids, as identified by several studies in different plant species. In T. fournieri, the cysteine-rich peptides (CRPs) TfLURE1 and TfLURE2, from the defensin-like protein subgroup, have been identified as attractant molecules that induce micropylar guidance (Okuda et al., 2009), and are capable of also attracting PTs in vitro (Higashiyama, 2010). LURES have also been identified in Arabidopsis (AtLURES), A. lyrata (AlLURES) (Takeuchi and Higashiyama, 2012), and T. concolor (TcCRP1) (Kanaoka et al., 2011). In Arabidopsis, these small proteins, which are only expressed in the synergids, are secreted through the filiform apparatus (Takeuchi and Higashiyama, 2012). The mutants magatama3 (Shimizu and Okada, 2000), myb98 (Kasahara et al., 2005), and central cell guidance (Chen et al., 2007) have been found to be defective in micropylar guidance due to an absence of AtLURE1 expression, indicating that it controls PT attraction (Takeuchi and Higashiyama, 2012). The novel interaction partner of the transcription factor CCG, the CCG-binding protein CBP1, seems to co-regulate the expression level of a subset of CRPs, including LURES, by recruiting the Mediator complex and RNA Pol II with CCG in the central cell (Li et al., 2015). Diverse genes expressed in the central cell and synergid are down-regulated in $c c g$ ovules such as MYB98, which is responsible for regulation of transcription of LUREs. Mutation of MAA3 affects PT attraction in Arabidopsis. MAA3 encodes a Sen1p-like RNA helicase and is believed to control target mRNA molecules whose products are needed to guide PTs (Shimizu et al., 2008). Moreover, recombinant AtLURE1 peptides expressed in Torenia are capable of attracting Arabidopsis PTs when Torenia ovules are placed in vitro close to the tip of Arabidopsis PTs (Takeuchi and Higashiyama, 2012). These peptides are therefore sufficient to overcome reproductive barriers in ovule orientation even between distant species (Mizuta and Higashiyama, 2018).

Unfertilized Arabidopsis ovules send diffusible attractant molecules (Palanivelu and Preuss, 2006; Takeuchi and Higashiyama, 2012), but these are no longer produced when the ovule is penetrated by a PT, which may in itself be sufficient to prevent the attraction of more PTs. But PTs may also be able to rapidly release diffusible repellents, although there is no firm evidence for this yet (Palanivelu and Preuss, 2006).

The specific Zea mays EGG APPARATUS1 gene (ZmEA1) encodes a small protein that is present not only in the synergids but also in the egg cell, the filiform apparatus, and the micropylar nucellus, and is necessary for micropylar orientation (Márton et al., 2005, 2012). No homologous candidate has been found in Arabidopsis, but there is no doubt about the importance of embryo sac cells for successful PT guidance.

GAMETE-EXPRESSED3 (GEX3) encodes a membrane protein and is expressed both in male and female tissues. Micropylar PT guidance defects are caused by aberrant expression of GEX3 in the egg cell (Kanaoka and Higashiyama, 2015).

As evidenced by immunolocalization studies in ovules and the filiform apparatus of synergids of different species, AGPs are also present in these tissues as attractant and/or signalling molecules for PT guidance (Coimbra and Salema, 1997; Coimbra and Duarte, 2003; Coimbra et al., 2007; Lopes et al., 2016). AGP23 is present at high levels inside the embryo sac upon fertilization where the PT bursts (Pereira et al., 2016a).

The JAGGER protein, AGP4, is essential in preventing the attraction of multiple pollen tubes to a single ovule (known as polytubey). The jagger persistent synergid does not undergo PCD and more than one PT is attracted to the ovule, in a polytubey effect. JAGGER controls the persistent synergid death and ends the multiple PTs attraction (Pereira et al., 2016b).

Arabidopsis has LURE1 receptors such as leucine-rich repeat (LRR) kinase-type receptors (RLKs), including MALE DISCOVERER 1 (MDIS1), MDIS1-INTERACTING LIKE KINASE RECEPTOR (MIK1, MIK2) (Wang et al. 2016), and POLLEN RECEPTOR-LIKE KINASE 6 (PRK6) (Takeuchi and Higashiyama, 2016). The recombinant AtLURE1 may induce heterodimerization of MDIS, MIK1, and MIK2 (Wang et al., 2016). These three receptors are located at the PT plasma membrane and knock-out lines exhibit defects in micropylar guidance. The tip-locailized pollen-specific receptor-like kinase 6 (PRK6) is essential for the detection of AtLURE1, and hence controls the atraction response and elongation of the PT (Takeuchi and Higashiyama (2016). The detection of AtLURE1 by PRK6 is achieved in cooperation with other PRK family receptors such as PRK1, PRK3, and PRK8, but PRK6 is the key receptor. PRK6 also interacts with pollenexpressed ROPGEFs (Rho of plant guanine nucleotideexchange factors), which are important for PT growth through activation of the signalling switch Rho GTPase ROP1 (Kaothien et al., 2005; Zhang and McCormick, 2007; Takeuchi and Higashiyama, 2016).

PT guidance is also affected by nitric oxide $(\mathrm{NO})$ and D-serine. NO has diverse effects on plant development as a growth regulator, and acts as a negative chemotropic cue during in vitro $\mathrm{PT}$ growth and re-orientation, which is mediated by a cGMP signalling pathway (Prado et al., 2004). Mutations in Arabidopsis NITRIC OXIDE SYNTHASE1 (AtNOS1) affect NO production and result in low fertility (Guo et al., 2003), indicating that $\mathrm{NO}$ has potential functions during PT guidance. Experiments with semi-in vivo isolated ovules and PTs have confirmed that NO is necessary for ovular PT guidance in Lilium longiflorum, with the pathway being dependent on $\mathrm{Ca}^{2+}$ signalling (Prado et al., 2008). It remains unclear how the PT surface perceives NO.

The $\mathrm{Ca}^{2+}$ signalling network is complex due to the existence of multiple $\mathrm{Ca}^{2+}$ channels, distinct regulation levels, and numerous PT $\mathrm{Ca}^{2+}$ sensors. Among other $\mathrm{Ca}^{2+}$ channels expressed in pollen, the Cyclic nucleotide-gated ion channel 18 (CNGC18) appears to be essential in PT growth and guidance (Frietsch et al., 2007). Examination of two point-mutations of cngc18 showed that the cyclic nucleotide (cNMP) activation of CNGC18 is probably involved in ovular guidance, but not in PT growth (Gao et al., 2016). Thus, $\mathrm{Ca}^{2+}$ influx may regulate the growth and guidance of the PT in a dual manner: basal influx for PT growth, and cNMP-activated influx for PT reorientation (Li et al., 2018).

LOST IN POLLEN TUBE GUIDANCE 1 (LIP1) and LIP2 are also involved in the AtLURE1-dependent orientation 
mechanism (Liu et al., 2013; Pereira et al., 2016a; Higashiyama, 2018). Due to the lack of a specific extracellular region, LIPs do not bind directly to the attractant molecules, including the AtLURE1 peptides, but they may form complexes with direct receptors of the LURE peptides, and thus act in signal transduction in the PT cytoplasm (Takeuchi and Higashiyama, 2016).

It is also important to map distinct proteins from the endoplasmic reticulum (ER), since their folding may be important for PT competence, enabling it to respond to attraction or orientation signals (Braakman and Herbert, 2013). POLLEN DEFECTIVE IN GUIDANCE 1 (POD1) is an ER protein that interacts with the chaperone CALRETICULIN 3 (CRT3) to control folding of the PT membrane proteins and to regulate their signalling (Li et al., 2011). Several molecules act in an intrinsic signalling pathway during the micropylar guidance stage, but knowledge of their composition and interactions is sparse (Pereira et al., 2016a; Mizuta and Higashiyama, 2018) and further research is needed.

\section{The treasure beyond the synergids}

At the end of its journey, the PT reaches the micropyle of its target ovule, enters the embryo sac through one of the synergids, stops its growth, and bursts to release the two male gametes (Leshem et al., 2013) that will fuse with the female ones; meanwhile the systems act to prevent multiple PTs converging on the ovule (Fig. 6). The receptive synergid undergoes PCD shortly before or upon entry of the PT (Faure et al., 2002). Through a complex signalling system and communication between the PT and the female tissues, the ultimate goal of generating a new seed is achieved, and the reproductive success of the plant is enabled (Pereira et al., 2016a).

Synergids gather the utmost point of PT attractant molecules and are able to receive and rupture it. The first PT receptor discovered, from the synergid filiform apparatus, was a serine/ threonine-type FERONIA/SIRENE (FER/SRN). The fer/ $s r n$ mutation leads to continuous growth of the PT within the embryo sac, with no release of the male gametes (Huck et al., 2003; Escobar-Restrepo et al., 2007; Rotman et al., 2008).

FER is a receptor-like kinase (RLK) from the Catharanthus roseus CrRLK1L-1 subfamily with an extracellular segment similar to a malectin domain, meaning that its binding molecule can be a carbohydrate or a cell wall glycoprotein (Lindner et al., 2012; Pereira et al., 2016a). FER is an essential factor in stopping the growth of the PT, its reception by the synergid, and its correct rupture and release of the gametes, and it may

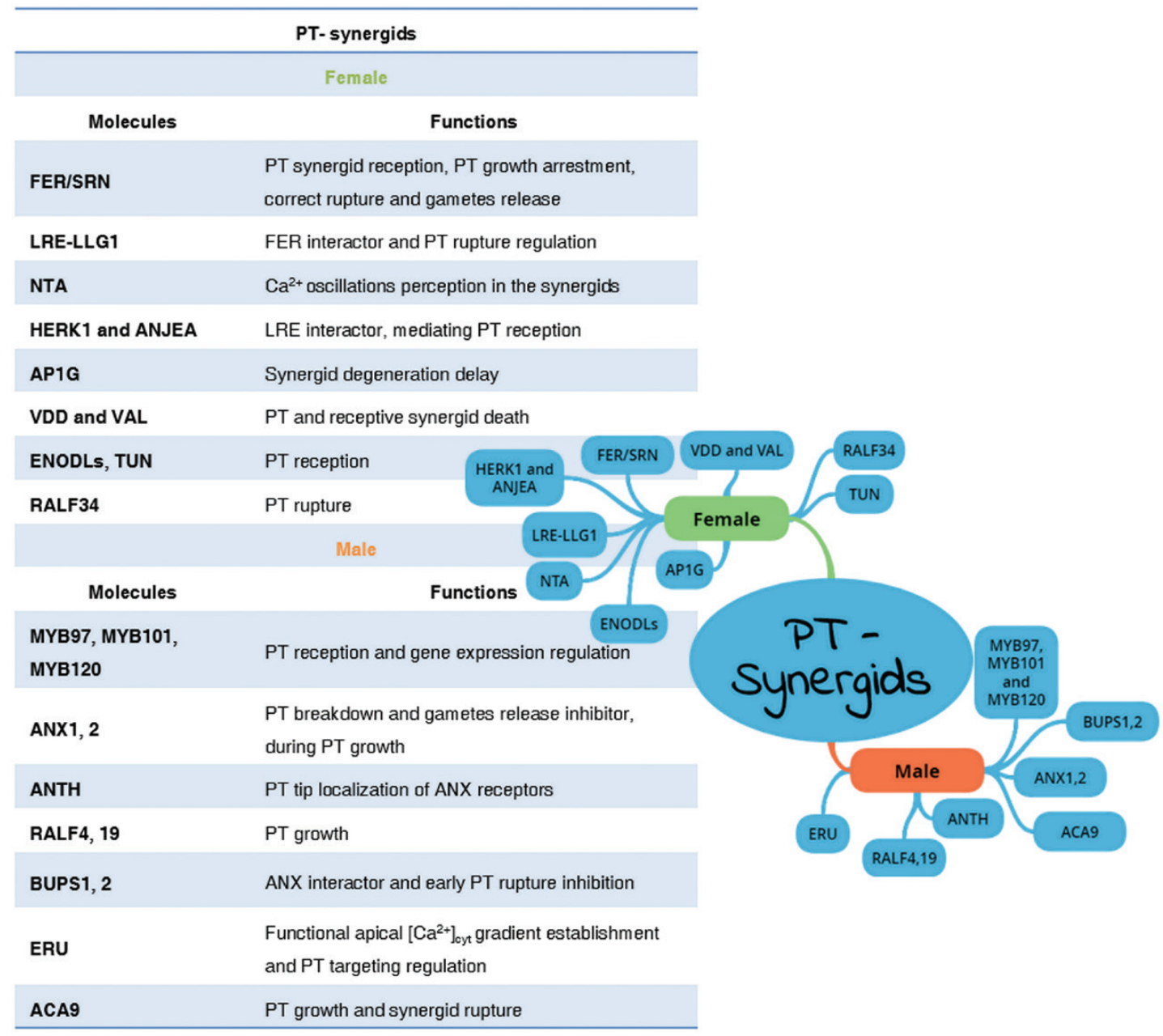

Fig. 6. The players involved during the interaction between the (PT) and the synergids and their roles. 
also be the link between extracellular events and intracellular orientation (Stegmann et al., 2017).

LORELEI (LRE) is a GPI anchor protein predominantly expressed in the synergids and the lre mutant has a similar phenotype to the $\mathrm{fer} / \mathrm{srn}$ mutation (Capron et al., 2008). LRE and FER work together in the reception of the PT by the synergid, with LRE acting as a co-receptor with FER (Hafidh et al., 2016; Liu et al., 2016). LRE and LLG1 (LORELEI-like GPI anchored protein 1) interact with FER in the ER lumen and act as chaperones to conduct FER to the filiform apparatus and to regulate rupture of the PT (Li et al., 2015).

NORTIA (NTA) also has a fer-like phenotype (Kessler et al., 2010). NTA acts in a FER-dependent way in the same signalling cascade. Its $\mathrm{C}$-terminal calmodulin domain suggests it is able to perceive $\mathrm{Ca}^{2+}$ oscillations in the synergids (Iwano et al., 2012). Both the lre and nta mutants have a similar phenotype to the fer mutant, but not fully penetrant as this last one. They play important roles in the PT-synergid interaction, but they may be acting redundantly with another as yet unknown factor that still needs to be identified before we can fully understand this signalling mechanism (Pereira et al., 2016a).

In Arabidopsis, in parallel to the FER signaling pathway, vacuolar acidification in synergid cells is impaired under low expression levels of AP1G, the $\gamma$-subunit of the tetrameric ADAPTOR PROTEIN1 (AP1). As a result, there is a delay in synergid cell degeneration upon arrival of the PT.AP1 regulates protein sorting at the trans-Golgi network/early endosome. In synergids cells with functional loss ofV-ATPases, the ap $1 \mathrm{~g} \mathrm{mu-}$ tant has a defect in the reception of the PT, indicating that acidification of the vacuole represents an important mechanism in synergid degeneration (Wang et al., 2017).

Other female gametophyte CrRLK1L receptors involved in the perception of the PT have been found(Galindo-Trigo et al., 2018, Preprint). HER CULES RECEPTOR KINASE1 (HERK1) and ANJEA (ANJ) are strongly localised at the filiform apparatus of the synergid cells, and the herk1 anj doublemutant shows over-growth of the PT inside the female gametophyte without rupture. Yeast two-hybrid assays show that the extracellular membrane domains of HERK1 and ANJ interact with LRE, leading the assumption that HERK1-LRE and ANJ-LRE may belong to a receptor complex in the filiform apparatus that is responsible for mediating the reception of the PT.

TURAN (TUN), encoding a UDP-glycosyltransferase protein, may also be involved in reception of the PT by the synergid, with a mutation that again shows a phenotype with over-growth of the PT inside the female gametophyte without rupture (Lindner et al., 2015). The VERDANDI (VDD) TF belongs to the Reproductive Meristem (REM) family, and $v d d$ shows defects in the cellular identity of the antipodals and synergids, with no PT rupture and thus continuation of its growth after reaching the synergids (MatiasHernandez et al., 2010). Recently, VDD and VALKYRIE (VAL, also a REM family member) have been shown to act as a complex that regulates the death of the receptive synergid, and also the death of the PT when it bursts (Mendes et al., 2016).
A small group of chimeric AGPs, the EARLY NODULINLIKE (ENODLs), EN11-EN15, are essential for the reception of the PT in Arabidopsis, with high expression levels found in the funiculus and in the ovules. EN14 and EN15 are present in the synergid filiform apparatus. The quintuple-mutant shows a similar phenotype to the fer mutant, with EN15 at least interacting with FER and hence perhaps being involved in the activation of the signalling pathway that is essential for the coordination of the male-female communication needed in the double-fertilization process (Hou et al., 2016).

There are also male players involved in the reception by the synergids and the rupture of the PT, clearly interacting in a coordinated way with the female players. The first identified set of pollen-specific MYB transcription factors, namely MYB97, MYB101, and MYB120, act to control the reception of the PT and to regulate its gene expression, including genes encoding the secretion of small peptides (Liang et al., 2013).

The $\mathrm{Ca}^{2+}$ pump ACA9 expressed in the PT has also been shown to regulate PT growth and rupture in the synergid (Schiott et al., 2004).

ANXUR 1 (ANX1) and ANX2 are receptor-like kinases and FER homologues that induce the PT to burst (BoissonDernier et al., 2009). When the receptive synergid goes into PCD, $\mathrm{Ca}^{2+}$ responses are activated (Boisson-Dernier et al., 2013, Ngo et al., 2014). The over-expression of ANX1/ANX2 receptors at the plasma membrane of the PT tip leads to its growth being blocked as a result of excessive activation of exocytosis and accumulation of secreted material by the cell wall. The anx 1 anx 2 double mutant stops PT development by premature rupturing of the tip (Boisson-Dernier et al., 2013). It has been established that ANX blocks the rupturing of the PT, and hence premature release of the gametes, by maintaining cell wall integrity, so it continues to grow in the female tissues until it reaches the FG (Boisson-Dernier et al. 2009; Miyazaki et al., 2009; Pereira et al., 2016a). Muro et al. (2018) have shown that the localization of ANX receptors in the PT tip is strictly mediated by two ANTH domain-containing proteins via the clathrin-mediated endocytosis pathway. The phosphatidylinositol binding clathrin assembly protein $5 a$ (picalm $5 a$ ) picalm $5 b$ doublemutant exhibits an altered distribution of ANX receptors in the PT and has an identical phenotype to anx1 anx2, i.e. premature bursting of PTs during their growth.

There has to be an extremely coordinated mechanism of signalling between the female and male cells during these interactions. Once in the FG, the FER-dependent signalling cascade located in the synergid is activated to mediate the reception of the PT and the fertilization process, while the ANXdependent signalling present in the PT is blocked, enabling the PT to rupture and release the gametes (Boisson-Dernier et al., 2009; Miyazaki et al., 2009). This is an interesting example of duplicate sibling genes of an ancestral gene working on cells of the opposite sex during male-female interactions (Higashiyama, 2018).

RAPID ALKALINIZATION FACTORs (RALFs) are secreted peptides that function as extracellular signals and are translated into the cell. These peptides are spread across the plant kingdom and Arabidopsis has 37 members (Murphy 
and De Smet, 2014) regulating various physiological processes (Stegmann et al., 2017).

The expression of RALF peptides in PTs was examined by Mecchia et al. (2017), who selected RALF4 and RALF19, the closest homologues, as the focus of their study. The ralf4 ralf19 double-mutant shows a similar phenotype to an $x 1$ an $x 2$, i.e. no maintenance of PT growth. Thus, RALF4/19 are crucial for growth of the PT, and possibly act upstream of ANX1/2.

Searching for additional CrRLK1Ls involved in PT reception, Ge et al. (2017) found two new receptors predominantly expressed in the PT, namely BUPS1 and BUPS2, and determined that the bups 1 bups 2 double-mutant has a similar phenotype to anx1 anx2. It is possible to find RALF4/19 interacting with BUPS1/2 and these two peptides interacting with ANX1/2. In addition, BUPS1/2 and ANX1/2 interact with each other. Given that the same premature-rupture phenotype of the PT is shown by the anx 1 anx 2 and bups 1 bups 2 double-mutants, a model may be suggested in which ANX1/2 and BUPS/2 form a heterodimer. Further studies are needed to determine whether RALF4/19 binding induces heterodimerization of ANX and BUPS. RALF34, expressed only in the female tissues, is the closest homolog of RALF4/19 and induces PT rupture at $2 \mathrm{nM}$ concentration, whereas RALF4/19 show no activity even at $20 \mu \mathrm{M}$. RALF34 competes with RALF4/19 in vitro in the BUPS1-ANX interaction, and so it can control PT rupture through the female tissues; however, we do not yet understand how this happens, and further studies are needed (Liang and Zhou, 2018).

The autocrine signalling mediated by RALF4/19 and ANX-BUPS is critical for maintaining long-distance growth of the PT and for the cell wall integrity of its tip. Questions remaining to be answered are how the external autocrine and paracrine signals for the PT tip change during its long journey and how the PTs respond to them (Higashiyama, 2018).

The improved understanding of the PT guidance and fertilization process includes a limited number of molecular players. Considering the FER and ANXUR1/2 description and their role in $\mathrm{Ca}^{2+}$-mediated fertilization, members of the CrRLK1L family had stepped into the regulation of polarized growth. ERULUS (ERU), also a CrRLK1L protein, has been described as a core regulator of root hairs and is involved in the establishment of a functional apical $\left[\mathrm{Ca}^{2+}\right]_{\text {cyt }}$ gradient (Bai et al., 2014). Pollen of the eru mutant are less competitive in vivo than wild-type pollen in terms of plant fertilization efficiency (Schoenaers et al., 2017) and show aberrant ovule-targeting of PTs, with more mutant PTs growing around the funiculus with multiple turns before targeting the micropyle. This is a similar phenotype to the lip1 lip2 double-mutant, which is defective in two PT plasma membrane-localized RLKs (Liu et al., 2013). LIP1 and LIP2 are crucial players in the receptor complex that regulates $\mathrm{PT}$ guidance in response to the micropyle-secreted AtLURE1 signalling peptide. It could therefore be suggested that ERU could function as a LURE receptor, and as such it could regulate PT targeting in a complex with LIP1 and LIP2 (Schoenaers et al., 2017).

After all the PT-synergid interactions, the PT ruptures and releases its contents, allowing the fusion of the male and female gametes (Fig. 7). For successful fusion to occur, three crucial players interact: GAMETE EXPRESSED 2 (GEX2), GENERATIVE CELL SPECIFIC 1/HAPLESS 2 (GSC1/ HAP2), and EGG CELL1 (EC1) (Mori et al., 2006; von Besser et al., 2006; Sprunck et al., 2012). GEX2 encodes a membraneexpressed protein of the male gametes that contains extracellular immunoglobulin-like domains required for gamete fusion (Mori et al., 2014). When male gametes with the gcs1 hap2 double-mutation are delivered to the ovules they cannot initiate fertilization, and the released gametes remain in the fusion site together with the female gametes, eventually leading to the attraction of multiple PTs (Mori et al., 2006; von Besser et al., 2006).EC1 is a cysteine-rich protein and is a possible activating molecule of the male gametes that permits fusion.ec1 quintuplemutants show that successful male-female gamete interactions prevent multiple sperm-cell delivery (Sprunck et al., 2012).

Respiratory burst oxidase homologue $\mathrm{H}(\mathrm{RBOHH})$ and $\mathrm{RBOHJ}$ have been found to act downstream of ANXs to control ROS production during PT growth (Boisson-Dernier et al., 2013). The tube-burst phenotype of both the anx1 anx2 and rbohh rbohJ double-mutants can be suppressed by a point-mutation (MRIR ${ }^{240 C}$ ) in the receptor-like cytoplasmic kinase MARIS (MRI) (Boisson-Dernier et al. 2015), while

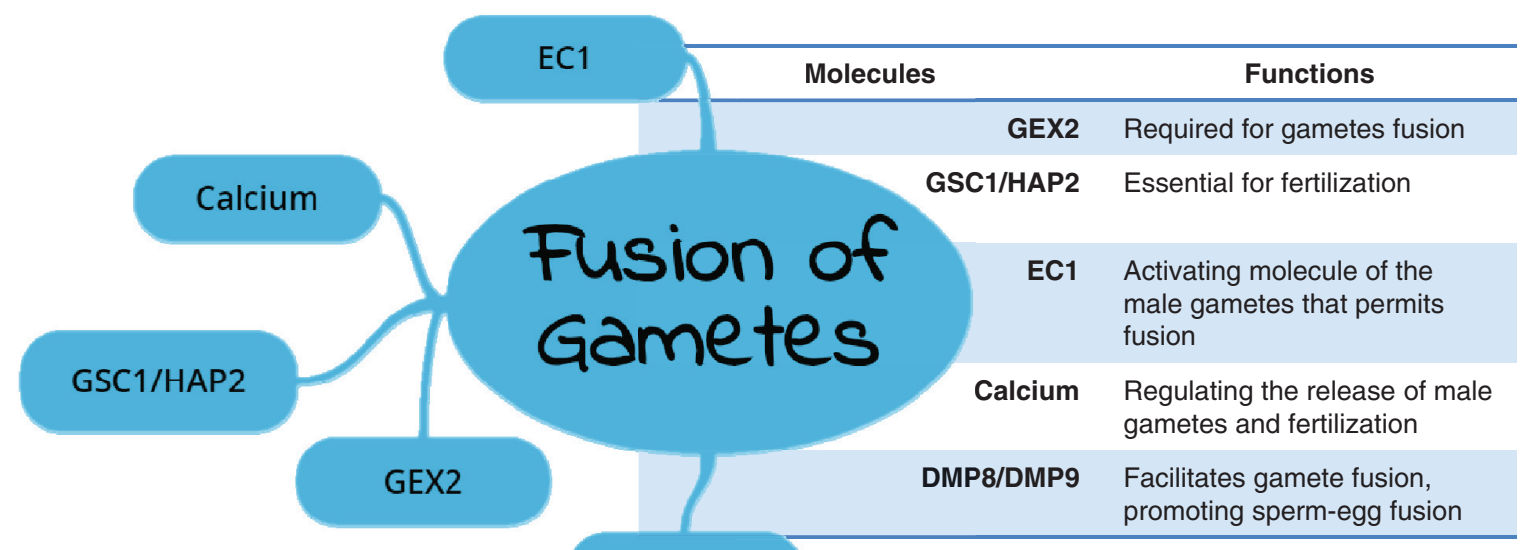

DMP8/DMP9

Fig. 7. The players involved during fusion of the gametes and their roles. 
RALF4 and 19 have been shown to function upstream of MRI (Mecchia et al., 2017). Thus, the RALF-BUPS/ANX complex may be regulating downstream $\mathrm{RBOHH}, \mathrm{RBOHJ}$, and MRI to maintain the integrity of the PT during its growth. Moreover, RALF4 and 19 bind the cell wall extensins LRX8, LRX9, and LRX11, which are expressed in the PT and have a vital role in the deposition of cell wall material (Mecchia et al., 2017).

A preponderant role is again played by $\mathrm{Ca}^{2+}$ in regulating the release of the male gametes and in fertilization (Iwano et al., 2012). Several molecules initiate their signalling mechanisms and interactions after $\mathrm{Ca}^{2+}$ oscillation events. Specific signatures of this secondary messenger are essential in the control of the PT and the PCD of the receptive synergid, in the fusion of the male and female gametes, and hence in the ultimate success of the double-fertilization process (Denninger et al., 2014; Ngo et al., 2014).

\section{Conclusions and outlook}

The pathway followed by the pollen tube from the surface of the stigma to the ultimate generation of a new seed is long and varied. The journey encompasses a complex genetic network of regulatory signals and refined cross-talk that provide step-by-step guidance towards the ovule. In this review, we have tried to map this pathway and present it as a series of clear and simple steps, and to highlight where gaps exist in our knowledge.

A broader description of the signalling pathways would certainly include the interactions that exist between the hormonal-signalling control of the positioning of tissue domains and the complex genetic regulatory network of the double-fertilization process, and consider the reciprocal dependency of the pollen tube on the transmitting tissue. A separate review could be written on the roles of $\mathrm{Ca}^{2+}$, which is present during all the stages of the double-fertilization process, and the AGP family, which is responsible for vital interactions at each step. New key players are still being discovered, helping to complete the overall picture of the network of male-female cross-talk during this sexual plant reproduction process.

\section{Acknowledgements}

Our work was supported by EU project 690946 'SexSeed' (Sexual Plant Reproduction - Seed Formation) funded by H2020-MSCA-RISE-2015. ALL received a FCT PhD grant (SFRH/BD/115960/2016), and AMP received a grant from the European Union's MSCA-IF-2016 project (no. 753328). The authors declare that they have no conflicts of interest in writing this review.

\section{References}

Alvarez J, Smyth DR. 2002. CRABS CLAW and SPATULA genes regulate growth and pattern formation during gynoecium development in Arabidopsis thaliana. International Journal of Plant Sciences 163, 17- 41.

Bai L, Ma X, Zhang G, Song S, Zhou Y, Gao L, Miao Y, Song CP. 2014. A receptor-like kinase mediates ammonium homeostasis and is important for the polar growth of root hairs in Arabidopsis. The Plant Cell 26, 1497-1511.
Beale KM, Johnson MA. 2013. Speed dating, rejection, and finding the perfect mate: advice from flowering plants. Current Opinion in Plant Biology 16 (5), 590-597.

Bedinger PA, Broz AK, Tovar-Mendez A, McClure B. 2017. PollenPistil interactions and their role in mate selection. Plant Physiology 173(1), 79-90.

Boex-Fontvieille E, Rustgi S, Reinbothe S, Reinbothe C. 2015. A Kunitz-type protease inhibitor regulates programmed cell death during flower development in Arabidopsis thaliana. Journal of Experimental Botany 66, 6119-6135.

Boisson-Dernier A, Franck CM, Lituiev DS, Grossniklaus U. 2015. Receptor-like cytoplasmic kinase MARIS functions downstream of CrRLK1L-dependent signaling during tip growth. Proceedings of the National Academy of Sciences, USA 112, 12211-12216.

Boisson-Dernier A, Lituiev DS, Nestorova A, Franck CM, Thirugnanarajah S, Grossniklaus U. 2013. ANXUR receptor-like kinases coordinate cell wall integrity with growth at the pollen tube tip via NADPH oxidases. PLoS Biology 11, e1001719.

Boisson-Dernier A, Roy S, Kritsas K, Grobei MA, Jaciubek M, Schroeder JI, Grossniklaus U. 2009. Disruption of the pollen-expressed FERONIA homologs ANXUR1 and ANXUR2 triggers pollen tube discharge. Development 136, 3279-3288.

Bosch M, Hepler PK. 2005. Pectin methylesterases and pectin dynamics in pollen tubes. The Plant Cell 17, 3219-3226.

Braakman I, Hebert DN. 2013. Protein folding in the endoplasmic reticulum. Cold Spring Harbor Perspectives in Biology 5, a013201.

Cameron C, Geitmann A. 2018. Cell mechanics of pollen tube growth. Current Opinion in Genetics \& Development 51, 11-17.

Capron A, Gourgues M, Neiva LS, et al. 2008. Maternal control of malegamete delivery in Arabidopsis involves a putative GPI-anchored protein encoded by the LORELEl gene. The Plant Cell 20, 3038-3049.

Chae K, Kieslich CA, Morikis D, Kim SC, Lord EM. 2009. A gain-offunction mutation of Arabidopsis lipid transfer protein 5 disturbs pollen tube tip growth and fertilization. The Plant Cell 21, 3902-3914.

Chapman LA, Goring DR. 2011. Misregulation of phosphoinositides in Arabidopsis thaliana decreases pollen hydration and maternal fertility. Sexual Plant Reproduction 24(4), 319-326.

Chen YH, Li HJ, Shi DQ, Yuan L, Liu J, Sreenivasan R, Baskar R, Grossniklaus U, Yang WC. 2007. The central cell plays a critical role in pollen tube guidance in Arabidopsis. The Plant Cell 19, 3563-3577.

Cheung AY, Wang H, Wu HM. 1995. A floral transmitting tissue-specific glycoprotein attracts pollen tubes and stimulates their growth. Cell $\mathbf{8 2}$, 383-393.

Coimbra S, Almeida J, Junqueira V, Costa ML, Pereira LG. 2007. Arabinogalactan proteins as molecular markers in Arabidopsis thaliana sexual reproduction. Journal of Experimental Botany 58, 4027-4035.

Coimbra S, Duarte C. 2003. Arabinogalactan proteins may facilitate the movement of pollen tubes from the stigma to the ovules in Actinidia deliciosa and Amaranthus hypochondriacus. Euphytica 133, 171-178.

Coimbra S, Salema R. 1997. Immunolocalization of arabinogalactan proteins in Amaranthus hypochondriacus L. ovules. Protoplasma 199, 75-82.

Costa M, Nobre MS, Becker JD, Masiero S, Amorim MI, Pereira LG, Coimbra S. 2013. Expression-based and co-localization detection of arabinogalactan protein 6 and arabinogalactan protein 11 interactors in Arabidopsis pollen and pollen tubes. BMC Plant Biology 13, 7.

Crawford BC, Ditta G, Yanofsky MF. 2007. The NTT gene is required for transmitting-tract development in carpels of Arabidopsis thaliana. Current Biology 17, 1101-1108.

Crawford BC, Yanofsky MF. 2008. The formation and function of the female reproductive tract in flowering plants. Current Biology 18, R972-R978.

Crawford BC, Yanofsky MF. 2011. HALF FILLED promotes reproductive tract development and fertilization efficiency in Arabidopsis thaliana. Development 138, 2999-3009.

Crepet WL. 2000. Progress in understanding angiosperm history, success, and relationships: Darwin's abominably 'perplexing phenomenon'. Proceedings of the National Academy of Sciences, USA 97, 12939-12941.

Cyprys P, Lindemeier M, Sprunck S. 2019. Gamete fusion is facilitated by two sperm cell-expressed DUF679 membrane proteins. Nature Plants 5, 253-257. 
DaiXR, GaoXQ,Chen GH, Tang LL, Wang H,ZhangXS.2014. ABNORMAL POLLEN TUBE GUIDANCE1, an endoplasmic reticulum-localized mannosyltransferase homolog of GLYCOSYLPHOSPHATIDYLINOSITOL10 in yeast and PHOSPHATIDYLINOSITOL GLYCAN ANCHORBIOSYNTHESIS $B$ in human, is required for Arabidopsis pollen tube micropylar guidance and embryo development. Plant Physiology 165, 1544-1556.

Deb J, Bland HM, Østergaard L. 2018. Developmental cartography: coordination via hormonal and genetic interactions during gynoecium formation. Current Opinion in Plant Biology 41, 54-60.

Denninger P, Bleckmann A, Lausser A, Vogler F, Ott T, Ehrhardt DW, Frommer WB, Sprunck S, Dresselhaus T, Grossmann G. 2014. Malefemale communication triggers calcium signatures during fertilization in Arabidopsis. Nature Communications 5, 4645.

Dresselhaus T, Franklin-Tong N. 2013. Male-female crosstalk during pollen germination, tube growth and guidance, and double fertilization. Molecular Plant 6, 1018-1036.

Erbar C. 2003. Pollen tube transmitting tissue: place of competition of male gametophytes. International Journal of Plant Sciences 164, S265-S277.

Escobar-Restrepo JM, Huck N, Kessler S, Gagliardini V, Gheyselinck J, Yang WC, Grossniklaus U. 2007. The FERONIA receptorlike kinase mediates male-female interactions during pollen tube reception. Science 317, 656-660.

Faure JE, Rotman N, Fortuné P, Dumas C. 2002. Fertilization in Arabidopsis thaliana wild type: developmental stages and time course. The Plant Journal 30, 481-488.

Feijo JA, Malho R, Obermeyer G. 1995. Ion dynamics and its possible role during in vitro pollen germination and tube growth. Protoplasma $\mathbf{1 8 7}$ 155-167.

Foreman J, Demidchik V, Bothwell JH, et al. 2003. Reactive oxygen species produced by NADPH oxidase regulate plant cell growth. Nature 422, 442-446.

Frietsch S, Wang YF, Sladek C, Poulsen LR, Romanowsky SM Schroeder JI, Harper JF. 2007. A cyclic nucleotide-gated channel is essential for polarized tip growth of pollen. Proceedings of the National Academy of Sciences, USA 104, 14531-14536.

Fujii S, Kubo K, Takayama S. 2016. Non-self- and self-recognition models in plant self-incompatibility. Nature Plants 2(9), 16130.

Galindo-Trigo S, Blanco-Tourinan N, DeFalco TA, Zipfel C, Gray JE, Smith LM. 2018. CrRLK1L receptor-like kinases HERK1 and ANJEA are female determinants of pollen tube reception. bioRxiv, 428854. [Preprint].

Gao QF, Gu LL, Wang HQ, Fei CF, Fang X, Hussain J, Sun SJ, Dong JY, Liu H, Wang YF. 2016. Cyclic nucleotide-gated channel 18 is an essential $\mathrm{Ca}^{2+}$ channel in pollen tube tips for pollen tube guidance to ovules in Arabidopsis. Proceedings of the National Academy of Sciences, USA 113, 3096-3101.

Ge Z, Bergonci T, Zhao Y, et al. 2017. Arabidopsis pollen tube integrity and sperm release are regulated by RALF-mediated signaling. Science $\mathbf{3 5 8}$, 1596-1600.

Goring DR. 2017. Exocyst, exosomes, and autophagy in the regulation of Brassicaceae pollen-stigma interactions. Journal of Experimental Botany 69(1), 69-78.

Guan Y, Lu J, Xu J, McClure B, Zhang S. 2014. Two mitogen-activated protein kinases, MPK3 and MPK6, are required for funicular guidance of pollen tubes in Arabidopsis. Plant Physiology 165, 528-533.

Guo FQ, Okamoto M, Crawford NM. 2003. Identification of a plant nitric oxide synthase gene involved in hormonal signaling. Science 302, 100-103.

Hafidh S, Fíla J, Honys D. 2016. Male gametophyte development and function in angiosperms: a general concept. Plant Reproduction 29, 31-51.

Hao L, Liu J, Zhong S, Gu H, Qu L-J. 2016. AtVPS41-mediated endocytic pathway is essential for pollen tube-stigma interaction in Arabidopsis. Proceedings of the National Academy of Sciences, USA 113, 6307-6312.

Hepler PK, Lovy WA, McKenna ST, Kunkel, JG. 2006. lons and pollen tube growth. The Plant Cell 3, 23.

Heslop-Harrison Y, Heslop-Harrison J, Reger BJ. 1985. The pollenstigma interaction in the grasses.7. Pollen-tube guidance and the regulation of tube number in Zea mays L. Acta Botanica Neerlandica 34, 193-211.

Heslop-Harrison J. 1987. Pollen germination and pollen-tube growth. International Review of Cytology 107, 1-78.
Higashiyama T. 2010. Peptide signaling in pollen-pistil interactions. Plant \& Cell Physiology 51, 177-189.

Higashiyama T. 2018. Plant reproduction: autocrine machinery for the long journey of the pollen tube. Current Biology 28, R266-R269.

Higashiyama T, Hamamura Y. 2008. Gametophytic pollen tube guidance. Sexual Plant Reproduction 21, 17-26.

Higashiyama T, Kuroiwa H, Kawano S, Kuroiwa T. 1998. Guidance in vitro of the pollen tube to the naked embryo sac of Torenia fournieri. The Plant Cell 10, 2019-2032.

Higashiyama T, Takeuchi H. 2015. The mechanism and key molecules involved in pollen tube guidance. Annual Review of Plant Biology 66, 393-413.

Higashiyama T, Yabe S, Sasaki N, Nishimura Y, Miyagishima S, Kuroiwa H, Kuroiwa T. 2001. Pollen tube attraction by the synergid cell. Science 293, 1480-1483.

Horade M, Kanaoka MM, Kuzuya M, Higashiyama T, Kaji N. 2013 A microfluidic device for quantitative analysis of chemoattraction in plants. RSC Advances 3, 22301-22307.

Hou Y, Guo X, Cyprys P, et al. 2016. Maternal ENODLs are required for pollen tube reception in Arabidopsis. Current Biology 26, 2343-2350.

Huang B-Q, Russell SD. 1992. Female germ unit: organization, isolation, and function. International Review of Cytology 140, 233-293.

Huck N, Moore JM, Federer M, Grossniklaus U. 2003. The Arabidopsis mutant feronia disrupts the female gametophytic control of pollen tube reception. Development 130, 2149-2159.

Iwano M, Ngo QA, Entani T, Shiba H, Nagai T, Miyawaki A, Isogai A, Grossniklaus U, Takayama S. 2012. Cytoplasmic $\mathrm{Ca}^{2+}$ changes dynamically during the interaction of the pollen tube with synergid cells. Development 139, 4202-4209.

Iwano M, Shiba H, Miwa T, Che FS, Takayama S, Nagai T, Miyawaki A, Isogai A. 2004. $\mathrm{Ca}^{2+}$ dynamics in a pollen grain and papilla cell during pollination of Arabidopsis. Plant Physiology 136, 3562-3571.

Jiang L, Yang SL, Xie LF, Puah CS, Zhang XQ, Yang WC, Sundaresan V, Ye D. 2005. VANGUARD1 encodes a pectin methylesterase that enhances pollen tube growth in the Arabidopsis style and transmitting tract. The Plant Cell 17, 584-596.

Kanaoka MM, Higashiyama T. 2015. Peptide signaling in pollen tube guidance. Current Opinion in Plant Biology 28, 127-136.

Kanaoka MM, Kawano N, Matsubara Y, Susaki D, Okuda S, Sasaki N, Higashiyama T. 2011. Identification and characterization of TcCRP1, a pollen tube attractant from Torenia concolor. Annals of Botany 108, 739-747.

Kasahara RD, Portereiko MF, Sandaklie-Nikolova L, Rabiger DS, Drews GN. 2005. MYB98 is required for pollen tube guidance and synergid cell differentiation in Arabidopsis. The Plant Cell 17, 2981-2992.

Kaothien P, Ok SH, Shuai B, Wengier D, Cotter R, Kelley D, Kiriakopolos S, Muschietti J, McCormick S. 2005. Kinase partner protein interacts with the LePRK1 and LePRK2 receptor kinases and plays a role in polarized pollen tube growth. The Plant Journal 42, 492-503.

Kaya H, Nakajima R, Iwano M, et al. 2014. Ca ${ }^{2+}$-activated reactive oxygen species production by Arabidopsis RbohH and RbohJ is essential for proper pollen tube tip growth. The Plant Cell 26, 1069-1080.

Kessler SA, Shimosato-Asano H, Keinath NF, Wuest SE, Ingram G, Panstruga R, Grossniklaus U. 2010. Conserved molecular components for pollen tube reception and fungal invasion. Science 330, 968-971.

Kim S, Mollet JC, Dong J, Zhang KL, Park SY, Lord EM. 2003. Chemocyanin, a small basic protein from the lily stigma, induces pollen tube chemotropism. Proceedings of the National Academy of Sciences, USA 100, 16125-16130

Lamport DTA, Kieliszewski MJ, Showalter AM. 2006. Salt stress upregulates periplasmic arabinogalactan proteins: using salt stress to analyse AGP function. New Phytologist 169, 479-492.

Lamport DTA, Tan L, Held MA, Kieliszewski MJ. 2018. Pollen tube growth and guidance: Occam's razor sharpened on a molecular arabinogalactan glycoprotein Rosetta Stone. New Phytologist 217, 491-500.

Lassig R, Gutermuth T, Bey TD, Konrad KR, Romeis T. 2014. Pollen tube $\mathrm{NAD}(\mathrm{P}) \mathrm{H}$ oxidases act as a speed control to dampen growth rate oscillations during polarized cell growth. The Plant Journal 78, 94-106. 
Lennon KA, Roy S, Hepler PK, Lord E. 1998. The structure of the transmitting tissue of Arabidopsis thaliana (L.) and the path of pollen tube growth. Sexual Plant Reproduction 11, 49-59.

Leshem Y, Johnson C, Sundaresan V. 2013. Pollen tube entry into the synergid cell of Arabidopsis is observed at a site distinct from the filiform apparatus. Plant Reproduction 26, 93-99.

Leydon AR, Tsukamoto T, Dunatunga D, Qin Y, Johnson MA, Palanivelu R. 2015. Pollen tube discharge completes the process of synergid degeneration that is initiated by pollen tube-synergid interaction in Arabidopsis. Plant Physiology 169, 485-496.

Li C, Yeh FL, Cheung AY, Duan Q, Kita D, Liu M-C, Maman J, Luu EJ, Wu BW, Gates L. 2015. Glycosylphosphatidylinositol-anchored proteins as chaperones and co-receptors for FERONIA receptor kinase signaling in Arabidopsis. eLIFE 4, e06587.

Li HJ, Meng JG, Yang WC. 2018. Multilayered signaling pathways for pollen tube growth and guidance. Plant Reproduction 31, 31-41.

Li HJ, Xue Y, Jia DJ, Wang T, Hi DQ, Liu J, Cui F, Xie Q, Ye D, Yang WC. 2011. POD1 regulates pollen tube guidance in response to micropylar female signaling and acts in early embryo patterning in Arabidopsis. The Plant Cell 23, 3288-3302.

Li HJ, Yang WC. 2018. Ligands switch model for pollen-tube integrity and burst. Trends in Plant Science 23, 369-372.

Li HJ, Zhu SS, Zhang MX, Wang T, Liang L, Xue Y, Shi DQ, Liu J, Yang WC. 2015. Arabidopsis CBP1 is a novel regulator of transcription initiation in central cell-mediated pollen tube guidance. The Plant Cell 27, 2880-2893.

Li J, Yu M, Geng LL, Zhao J. 2010. The fasciclin-like arabinogalactan protein gene, FLA3, is involved in microspore development of Arabidopsis. The Plant Journal 64, 482-497.

Li S, Ge FR, Xu M, et al. 2013. Arabidopsis COBRA-LIKE 10, a GPIanchored protein, mediates directional growth of pollen tubes. The Plant Journal 74, 486-497.

Liang XX, Zhou JM. 2018. The secret of fertilization in flowering plants unveiled. Science Bulletin 63, 408-410.

Liang Y, Tan ZM, Zhu L, Niu QK, Zhou JJ, Li M, Chen LQ, Zhang XQ, Ye D. 2013. MYB97, MYB101 and MYB120 function as male factors that control pollen tube-synergid interaction in Arabidopsis thaliana fertilization. PLoS Genetics 9, e1003933.

Lindner H, Kessler SA, Müller LM, Shimosato-Asano H, BoissonDernier A, Grossniklaus U. 2015. TURAN and EVAN mediate pollen tube reception in Arabidopsis synergids through protein glycosylation. PLoS Biology 13, e1002139.

Lindner H, Müller LM, Boisson-Dernier A, Grossniklaus U. 2012. CrRLK1L receptor-like kinases: not just another brick in the wall. Current Opinion in Plant Biology 15, 659-669.

Liu J, Zhong S, Guo X, et al. 2013. Membrane-bound RLCKs LIP1 and LIP2 are essential male factors controlling male-female attraction in Arabidopsis. Current Biology 23, 993-998.

Liu X, Castro CA, Wang Y, Noble JA, Ponvert ND, Bundy MG, Hoel CR, Shpak ED, Palanivelu R. 2016. The role of LORELEl in pollen tube reception at the interface of the synergid cell and pollen tube requires the modified eight-cysteine motif and the receptor-like kinase FERONIA. The Plant Cell 28, 1035-1052.

Liu LT, Zheng CH, Kuang BJ, Wei LQ, Yan LF, Wang T. 2016. Receptorlike kinase RUPO interacts with potassium transporters to regulate pollen tube growth and integrity in rice. PLoS Genetics 12, e1006085.

Lopes AL, Costa ML, Sobral R, Costa MM, Amorim MI, Coimbra S. 2016. Arabinogalactan proteins and pectin distribution during female gametogenesis in Quercus suber L. Annals of Botany 117, 949-961.

Lora J, Laux T, Hormaza JI. 2019. The role of the integuments in pollen tube guidance in flowering plants. New Phytologist 221, 1074-1089.

Lord EM, Russell SD. 2002. The mechanisms of pollination and fertilization in plants. Annual Review of Cell and Developmental Biology 18, 81-105.

Losada JM, Herrero M. 2012. Arabinogalactan-protein secretion is associated with the acquisition of stigmatic receptivity in the apple flower. Annals of Botany 110, 573-584.

Losdat S, Chang SM, Reid JM. 2014. Inbreeding depression in male gametic performance. Journal of Evolutionary Biology 27, 992-1011.
Lu Y, Chanroj S, Zulkifli L, Johnson MA, Uozumi N, Cheung A, Sze H. 2011. Pollen tubes lacking a pair of $\mathrm{K}^{+}$transporters fail to target ovules in Arabidopsis. The Plant Cell 23, 81-93.

Lush WM. 1999. Whither chemotropism and pollen tube guidance? Trends in Plant Science 4, 413-418.

Maheshwari P, Johri BM. 1950. Development of the embryo sac, embryo and endosperm in Helixanthera ligustrina (Wall.) Dans. Nature 165, 978-979.

Márton ML, Cordts S, Broadhvest J, Dresselhaus T. 2005. Micropylar pollen tube guidance by egg apparatus 1 of maize. Science 307, 573-576.

Márton ML, Fastner A, Uebler S, Dresselhaus T. 2012. Overcoming hybridization barriers by the secretion of the maize pollen tube attractant ZmEA1 from Arabidopsis ovules. Current Biology 22, 1194-1198.

Matias-Hernandez L, Battaglia R, Galbiati F, Rubes M, Eichenberger C, Grossniklaus U, Kater MM, Colombo L. 2010. VERDANDI is a direct target of the MADS domain ovule identity complex and affects embryo sac differentiation in Arabidopsis. The Plant Cell 22, 1702-1715.

McCormick S. 1993. Male gametophyte development. The Plant Cell 5, 1265-1275.

McCormick S. 2004. Control of male gametophyte development. The Plant Cell 16, S142-S153.

Mecchia MA, Santos-Fernandez G, Duss NN, et al. 2017. RALF4/19 peptides interact with LRX proteins to control pollen tube growth in Arabidopsis. Science 358, 1600-1603.

Meinke DW. 1994. Seed development in Arabidopsis thaliana. Cold Spring Harbor Monograph Series 27, 253-253.

Mendes MA, Guerra RF, Castelnovo B, Silva-Velazquez Y, Morandini P, Manrique S, Baumann N, Groß-Hardt R, Dickinson H, Colombo L. 2016. Live and let die: a REM complex promotes fertilization through synergid cell death in Arabidopsis. Development 143, 2780-2790.

Miyazaki S, Murata T, Sakurai-Ozato N, Kubo M, Demura T, Fukuda H, Hasebe M. 2009. ANXUR1 and 2, sister genes to FERONIA/SIRENE, are male factors for coordinated fertilization. Current Biology 19, 1327-1331.

Mizukami AG, Inatsugi R, Jiao J, et al. 2016. The AMOR arabinogalactan sugar chain induces pollen-tube competency to respond to ovular guidance. Current Biology 26, 1091-1097.

Mizuta Y, Higashiyama T. 2018. Chemical signaling for pollen tube guidance at a glance. Journal of Cell Science 131, jcs208447.

Mori T, Igawa T, Tamiya G, Miyagishima SY, Berger F. 2014. Gamete attachment requires GEX2 for successful fertilization in Arabidopsis. Current Biology 24, 170-175.

Mori T, Kuroiwa H, Higashiyama T, Kuroiwa T. 2006. GENERATIVE CELL SPECIFIC 1 is essential for angiosperm fertilization. Nature Cell Biology 8, 64-71.

Mouline K, Véry AA, Gaymard F, Boucherez J, Pilot G, Devic M, Bouchez D, Thibaud JB, Sentenac H. 2002. Pollen tube development and competitive ability are impaired by disruption of a Shaker $\mathrm{K}^{+}$channel in Arabidopsis. Genes \& Development 16, 339-350.

Muro K M-TK, Tsukamoto R, Kanaoka M, Ebine K, Higashiyama T, Nakano A, Ueda T. 2018. ANTH domain-containing proteins are required for the pollen tube plasma membrane integrity via recycling ANXUR kinases. Nature Communications Biology 1, 152.

Murphy E, De Smet I. 2014. Understanding the RALF family: a tale of many species. Trends in Plant Science 19, 664-671.

Nasrallah JB. 2017. Plant mating systems: self-incompatibility and evolutionary transitions to self-fertility in the mustard family. Current Opinion in Genetics \& Development 47, 54-60.

Ngo QA, Vogler H, Lituiev DS, Nestorova A, Grossniklaus U. 2014. A calcium dialog mediated by the FERONIA signal transduction pathway controls plant sperm delivery. Developmental Cell 29, 491-500.

Okuda S, Tsutsui H, Shiina K, et al. 2009. Defensin-like polypeptide LUREs are pollen tube attractants secreted from synergid cells. Nature $\mathbf{4 5 8}$, 357-361.

Palanivelu R, Brass L, Edlund AF, Preuss D. 2003. Pollen tube growth and guidance is regulated by $P O P 2$, an Arabidopsis gene that controls GABA levels. Cell 114, 47-59.

Palanivelu R, Preuss D. 2006. Distinct short-range ovule signals attract or repel Arabidopsis thaliana pollen tubes in vitro. BMC Plant Biology 6, 7. 
Palanivelu R, Tsukamoto T. 2012. Pathfinding in angiosperm reproduction: pollen tube guidance by pistils ensures successful double fertilization. Wiley Interdisciplinary Reviews. Developmental Biology 1, 96-113.

Park SY, Jauh GY, Mollet JC, Eckard KJ, Nothnagel EA, Walling LL, Lord EM. 2000. A lipid transfer-like protein is necessary for lily pollen tube adhesion to an in vitro stylar matrix. The Plant Cell 12, 151-164.

Pereira AM, Lopes AL, Coimbra S. 2016a. Arabinogalactan proteins as interactors along the crosstalk between the pollen tube and the female tissues. Frontiers in Plant Science 7, 1895.

Pereira AM, Masiero S, Nobre MS, Costa ML, Solís MT, Testillano PS, Sprunck S, Coimbra S. 2014. Differential expression patterns of arabinogalactan proteins in Arabidopsis thaliana reproductive tissues. Journal of Experimental Botany 65, 5459-5471.

Pereira AM, Nobre MS, Pinto SC, Lopes AL, Costa ML, Masiero S, Coimbra S. 2016b. 'Love is strong, and you're so sweet': JAGGER is essential for persistent synergid degeneration and polytubey block in Arabidopsis thaliana. Molecular Plant 9, 601-614.

Pereira AM, Pereira LG, Coimbra S. 2015. Arabinogalactan proteins: rising attention from plant biologists. Plant Reproduction 28, 1-15.

Prado AM, Colaço R, Moreno N, Silva AC, Feijó JA. 2008. Targeting of pollen tubes to ovules is dependent on nitric oxide (NO) signaling. Molecular Plant 1, 703-714.

Prado AM, Porterfield DM, Feijó JA. 2004. Nitric oxide is involved in growth regulation and re-orientation of pollen tubes. Development 131, 2707-2714.

Punwani JA, Rabiger DS, Lloyd A, Drews GN. 2008. The MYB98 subcircuit of the synergid gene regulatory network includes genes directly and indirectly regulated by MYB98. The Plant Journal 55, 406-414.

Qu LJ, Li L, Lan Z, Dresselhaus T. 2015. Peptide signalling during the pollen tube journey and double fertilization. Journal of Experimental Botany 66, 5139-5150.

Ray SM, Park SS, Ray A. 1997. Pollen tube guidance by the female gametophyte. Development 124, 2489-2498.

Rotman N, Gourgues M, Guitton AE, Faure JE, Berger F. 2008. A dialogue between the SIRENE pathway in synergids and the fertilization independent seed pathway in the central cell controls male gamete release during double fertilization in Arabidopsis. Molecular Plant 1, 659-666.

Safavian D, Zayed Y, Indriolo E, Chapman L, Ahmed A, Goring DR. 2015. RNA Silencing of Exocyst Genes in the Stigma Impairs the Acceptance of Compatible Pollen in Arabidopsis. Plant Physiology 169(4), 2526-2538.

Schiott M, Romanowsky SM, Baekgaard L, Jakobsen MK, Palmgren MG, Harper JF. 2004. A plant plasma membrane $\mathrm{Ca}^{2+}$ pump is required for normal pollen tube growth and fertilization. Proceedings of the National Academy of Sciences, USA 101, 9502-9507.

Schoenaers S, Balcerowicz D, Costa A, Vissenberg K. 2017. The kinase ERULUS controls pollen tube targeting and growth in Arabidopsis thaliana. Frontiers in Plant Science 8, 1942.

Shimizu KK, Ito T, Ishiguro S, Okada K. 2008. MAA3 (MAGATAMA3) helicase gene is required for female gametophyte development and pollen tube guidance in Arabidopsis thaliana. Plant \& Cell Physiology 49, 1478-1483.

Shimizu KK, Okada K. 2000. Attractive and repulsive interactions between female and male gametophytes in Arabidopsis pollen tube guidance. Development 127, 4511-4518.

Smith DK, Jones DM, Lau JBR, Cruz ER, Brown E, Harper JF, Wallace IS. 2018. A putative protein O-fucosyltransferase facilitates pollen tube penetration through the stigma-style interface. Plant Physiology $\mathbf{1 7 6}$ 2804-2818.

Sogo A, Tobe H. 2006. Mode of pollen-tube growth in pistils of Myrica rubra (Myricaceae): a comparison with related families. Annals of Botany 97, 71-77.

Sommer-Knudsen J, Lush WM, Bacic A, Clarke AE. 1998. Re-evaluation of the role of a transmitting tract-specific glycoprotein on pollen tube growth. The Plant Journal 13, 529-535.

Sprunck S, Rademacher S, Vogler F, Gheyselinck J, Grossniklaus U, Dresselhaus T. 2012. Egg cell-secreted EC1 triggers sperm cell activation during double fertilization. Science 338, 1093-1097.
Stegmann M, Monaghan J, Smakowska-Luzan E, Rovenich H, Lehner A, Holton N, Belkhadir Y, Zipfel C. 2017. The receptor kinase FER is a RALF-regulated scaffold controlling plant immune signaling. Science 355, 287-289.

Stührwohldt N, Dahlke RI, Kutschmar A, Peng X, Sun MX, Sauter M. 2015. Phytosulfokine peptide signaling controls pollen tube growth and funicular pollen tube guidance in Arabidopsis thaliana. Physiologia Plantarum 153, 643-653.

Su S, Higashiyama T. 2018. Arabinogalactan proteins and their sugar chains: functions in plant reproduction, research methods, and biosynthesis. Plant Reproduction 31, 67-75.

Susaki D, Takeuchi H, Tsutsui H, Kurihara D, Higashiyama T. 2015. Live imaging and laser disruption reveal the dynamics and cell-cell communication during Torenia fournieri female gametophyte development. Plant \& Cell Physiology 56, 1031-1041.

Takahashi T, Mori T, Ueda K, Yamada L, Nagahara S, Higashiyama T, Sawada H, Igawa T. 2018. The male gamete membrane protein DMP9/ DAU2 is required for double fertilization in flowering plants. Development 145, 23.

Takeuchi H, Higashiyama T. 2012. A species-specific cluster of defensinlike genes encodes diffusible pollen tube attractants in Arabidopsis. PLoS Biology 10, e1001449.

Takeuchi H, Higashiyama T. 2016. Tip-localized receptors control pollen tube growth and LURE sensing in Arabidopsis. Nature 531, 245-248.

Tang W, Kelley D, Ezcurra I, Cotter R, McCormick S. 2004. LeSTIG1, an extracellular binding partner for the pollen receptor kinases LePRK1 and LePRK2, promotes pollen tube growth in vitro. The Plant Journal 39, 343-353.

Vogler F, Schmalzl C, Englhart M, Bircheneder M, Sprunck S. 2014. Brassinosteroids promote Arabidopsis pollen germination and growth. Plant Reproduction 27, 153-167.

von Besser K, Frank AC, Johnson MA, Preuss D. 2006. Arabidopsis HAP2 (GCS1) is a sperm-specific gene required for pollen tube guidance and fertilization. Development 133, 4761-4769.

Wang JG, Feng C, Liu HH, Feng QN, Li S, Zhang Y. 2017. AP1G mediates vacuolar acidification during synergid-controlled pollen tube reception. Proceedings of the National Academy of Sciences, USA 114, E4877-E4883.

Wang T, Liang L, Xue Y, Jia PF, Chen W, Zhang MX, Wang YC, Li HJ, Yang WC. 2016. A receptor heteromer mediates the male perception of female attractants in plants. Nature 531, 241-244.

Woriedh M, Wolf S, Márton ML, Hinze A, Gahrtz M, Becker D, Dresselhaus T. 2013. External application of gametophyte-specific ZmPMEl1 induces pollen tube burst in maize. Plant Reproduction 26, 255-266.

Winship LJ, Obermeyer G, Geitmann A, Hepler PK. 2011. Pollen tubes and the physical world. Trends in Plant Science 16, 353-355.

Wu H, de Graaf B, Mariani C, Cheung AY. 2001. Hydroxyproline-rich glycoproteins in plant reproductive tissues: structure, functions and regulation. Cellular and Molecular Life Sciences 58, 1418-1429.

Yadegari R, Drews GN. 2004. Female gametophyte development. The Plant Cell 16, S133-S141.

Yang J, Sardar HS, McGovern KR, Zhang Y, Showalter AM. 2007. A lysine-rich arabinogalactan protein in Arabidopsis is essential for plant growth and development, including cell division and expansion. The Plant Journal 49, 629-640.

Yu GH, Zou J, Feng J, Peng XB, Wu JY, Wu YL, Palanivelu R, Sun MX. 2014. Exogenous $\gamma$-aminobutyric acid (GABA) affects pollen tube growth via modulating putative $\mathrm{Ca}^{2+}$-permeable membrane channels and is coupled to negative regulation on glutamate decarboxylase. Journal of Experimental Botany 65, 3235-3248.

Zhang Y, McCormick, S. 2007. A distinct mechanism regulating a pollenspecific guanine nucleotide exchange factor for the small GTPase Rop in Arabidopsis thaliana. Proceedings of the National Academy of Sciences, USA 104, 18830-18835.

Zhou LZ, Dresselhaus T. 2019. Friend or foe: Signaling mechanisms during double fertilization in flowering seed plants. Current Topics in Developmental Biology 131, 453-496. 